\title{
The infamous coronary stent saga
}

\author{
Bernhard Meier \\ Cardiology, Cardiovascular Department, Bern University Hospital, Bern, Switzerland
}

\section{Summary}

Against all odds, as a foreign body in a coronary artery was considered too thrombogenic, coronary artery stents have become a standard feature of percutaneous coronary intervention (PCI). After initial reluctance to employ coronary stents based on misinterpretation of thrombosis rates when stents were exclusively used for bail-out procedures, stent overuse took over quickly. Balloon angioplasty results indicated that only $25 \%$ of lesions can possibly benefit from a stent. A stent implanted in the remaining $75 \%$ of lesions is without any chance to help but carries some risk to harm. However, the risk of harm has become so small with ever improving stents that default stenting has become acceptable. Avid stent implanters argue that only $100 \%$ stenting assures that the $25 \%$ of lesions needing a stent indeed get a stent. Shortly after drug-eluting stents (DES) had been introduced, they were falsely accused of being dangerous on the ground of their higher propensity for stent thrombosis after the first year compared to bare metal stents (BMS). In fact, they had significantly fewer early stent thromboses during the first year irrespective of the extent of antiplatelet therapy. This advantage was admittedly progressively lost over the years. Subsequent generations of DES enhanced this early reduction of stent thrombosis but no longer showed that late catch-up phenomenon. These facts are ignored or misinterpreted to the present date by most physicians and all guidelines and textbooks. It was always preferable to implant a DES rather than a BMS when there was concern about stent thrombosis, be it because of need of early surgery or another impossibility to maintain double antiplatelet therapy. The respective advantage of current generation DES is overwhelming so that using a BMS is close to unethical. The most recent misconception, i.e., the need to have an absorbable stent, is also principally based on the myth of DES to be overly thrombogenic. The current absorbable stents disappear at best after a few years when the risk of a late stent thrombosis with a modern DES is virtually nil. Other reasons for absorbable stents, such as restitution of normal histology and vasomotion, easy accessibility of the stented segment for later bypass graft insertion, less stent malapposition to the vessel wall, and reduced need for antiplatelet therapy are either wrong or clinically trivial.

$$
\text { (PCI) }
$$

Key words: Percutaneous coronary intervention

\section{Introduction}

We do not even know what the word stent means, no wonder we know even less how to best deal with this thing. Charles Stent, an English dentist who developed a bracing mold for oral surgery in 1856, is most likely the name's father [1]. He now not only features a common noun but also a verb named after him. Metallic implants (e.g., copper coils) had been used by early invasive cardiologists to experimentally thrombose coronary arteries. Using such an implant to prevent thrombotic closure appeared paradoxical. Andreas Gruentzig, the father of percutaneous coronary intervention (PCI), toyed with the idea of tacking the unavoidable intimal flap after peripheral or coronary balloon angioplasty to the wall with a metallic scaffold but gave it only a modest chance of success. It was not going to be his to witness the first human coronary stent implantation, let alone to perform it himself.

\section{History of coronary stenting}

Apart from Gruentzig's group, several other teams worked on the development of a scaffold to tame the ominous coronary dissection, the fundamental mechanism of balloon angioplasty, by preventing it from obstructing blood flow and causing a thrombus. Cesare Gianturco and Julio Palmas in the United States and Hans Wallsten in Switzerland were the minds behind the three original coronary stent designs. Hans Wallsten won the race when Jacques Puel implanted the

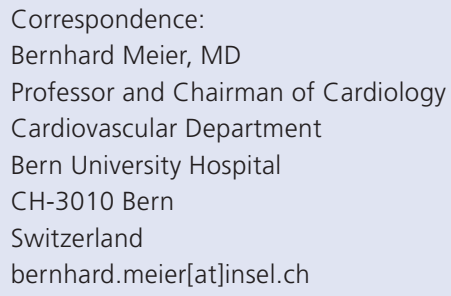


first of his coronary stents (named Wallstent, what else?) on 29 March 1986 in Toulouse, France [2], in an elective stent implantation to treat restenosis after balloon angioplasty. The principal idea behind the stent development, however, had been to use it as a bail-out device in case of a threatened or accomplished obstructive dissection after balloon angioplasty. Ulrich Sigwart in Lausanne was the first to use Wallstents to that end in the months following Puel's ground-breaking elective case. In the subsequent almost 30 years to the present day, stents have become a sine qua non of PCI and they have been refined based on the experience gathered with millions of patients. On top of improved profiles and flexibility for easy introduction, thrombogenicity has been drastically reduced and the feature of an antiproliferative drug, eluted during the first weeks to months, also curbed restenosis to a perfectly acceptable level.

\section{Clinical results of coronary stents and their many misinterpretations}

The stent held its promise when comparing the acute results of PCI before [3] and after [4] the advent of coronary stents. Mortality was reduced from 5\% to $1 \%$, myocardial infarction from $40 \%$ to $4 \%$, and need for emergency coronary artery bypass grafting from $40 \%$ to $1 \%$. Somewhat as a bonus, stenting also reduced restenosis (re-narrowing of the enlarged lumen by elastic recoil and overzealous endothelial proliferation), particularly in smaller vessels and short stent segments. Preventing recoil is the mechanism for that. Accounting for these facts, it could be deduced that about $25 \%$ of lesions should be stented. The mathematics are that $70 \%$ of lesions will neither suffer abrupt closure (risk of $7 \%$ without stent) nor clinically relevant restenosis (risk of about $25 \%$ with some overlap). Subtract from the resulting $30 \%$ about $5 \%$ of lesions that will have a problem in spite of a stent. Hence, the ideal interventional cardiologist should be able to anticipate the $25 \%$ of lesions needing and benefiting from a stent and not implant a stent in the remaining $75 \%$. This was the exact conclusion of a paper comparing restenosis reduction of randomised trials between plain old balloon angioplasty (POBA) and coronary stenting [5]. Moreover, a paper looking at the late outcomes in the first such randomised trial, the Belgian-NetherlandsStent (BeNeStent) study, even made out a prognostic disadvantage of placing stents into every lesion [6]. Such a strategy doubled mortality from $3 \%$ to $6 \%$ and infarction rate from $4 \%$ to $8 \%$. These papers were cavalierly ignored because they appeared in an era of early stent frenzy when the optical appeal of a stented compared to a fuzzy nonstented POBA lesion had already conquered virtually every interventional cardiologist's mind. So the community of interventional cardiologists misguidedly jeopardised patient outcome while increasing the cost of PCI for the sake of angiographically impeccable results and for their deficient capability to predict which lesion should and which lesion should not get a stent. This behaviour was ethically questionable until the stents got so much better and safer that putting one in a lesion that does not need it can no longer be called a threat.

\section{Drug-eluting stents and the restenosis bubble}

The so-called drug-eluting stents (DES) were a welcome and palpable improvement of the original bare metal stents (BMS). Yet, to make the DES advantage look better than it really was and to justify their prices

\section{Figure 1}

Restenosis rate of the Bx-Velocity bare metal stent and its drug-eluting successor, the Cypher stent, looking at studies performed in the era before (pre DES) and after introduction of the Cypher stent.

BMS = bare metal stents; DES = drug-eluting stents; E-SIRIUS [11] = Sirolimus-eluting stents for treatment of patients with long atherosclerotic lesions in small coronary arteries; Pts = patients; RAVEL [9] = Randomised study with the sirolimus-coated Bx-Velocity balloon-expandable stent in the treatment of patients with de novo native coronary artery lesions; SIRIUS [10] = Sirolimus-eluting balloon-expandable stent in the treatment of patients with de novo native coronary artery lesions; VELVET [8] = Direct stenting with the Bx-Velocity balloon-expandable stent mounted on the rapid exchange delivery system versus predilatation in a European randomised trial; VENUS [7] = Bx-Velocity stenting native coronary lesions in the United States.

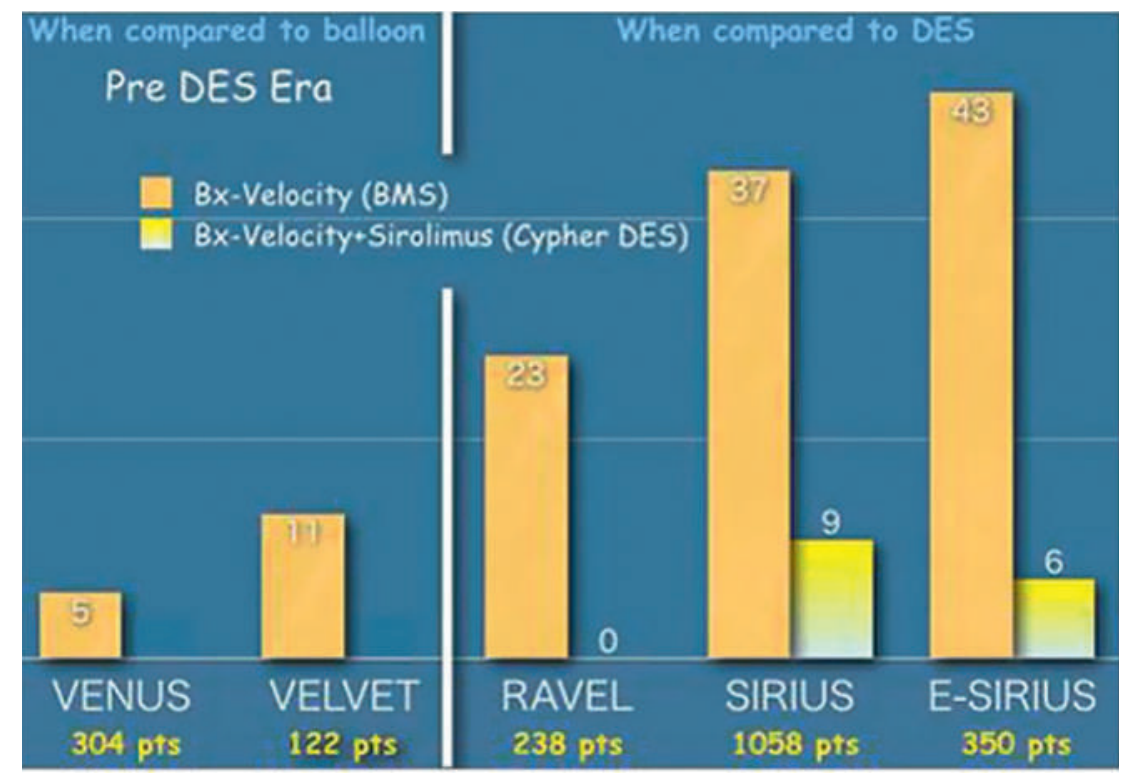


that amounted to more than double of those of BMS, opinion leaders applied what is generally used in such situations. The restenosis rate of BMS, shown to be between $10 \%$ and $30 \%$ in many scientific papers comparing BMS to POBA and causing a need for reintervention in about $5 \%$ to $10 \%$ [5], was boosted up to make the already remarkable single digit restenosis rate of early generation DES look really extraordinary. DES restenosis rate was presented on the background of "revised" BMS restenosis rates of $20 \%$ to $40 \%$, figures that had appeared nowhere before the advent of DES. Figure 1 [7-11] depicts that graphically, pertaining to the market-leading BMS at the time of DES introduction, the Bx-Velocity stent, which also was the platform of the first DES called Cypher.

Notwithstanding, the restenosis rate and the need for re-intervention were indeed reduced by DES compared to BMS. Even more importantly, the difficult-totreat long and diffuse in-stent restenoses have virtually disappeared with DES.

\section{Drug-eluting stents and the double-antiplatelet therapy myth}

Initially, stenting was used almost exclusively in bailout situations. The ensuing stent thrombosis rate was around $20 \%$. This was a remarkable success considering that before stents these situations had resulted in $>50 \%$ of vessel thrombosis. However, when looking at a $20 \%$ thrombosis rate in stented cases and comparing them to the thrombosis rate of elective POBA (about $7 \%$ ) or other devices being propagated in the $1980 \mathrm{~s}$ such as directional atherectomy or rotablation (about $10 \%$ each), the stent came in last for all the wrong reasons. Stenting was therefore taken up quite reluctantly particularly in the United States of America [12]. The traditional drug treatment at that time was oral anticoagulation with a vitamin $\mathrm{K}$ antagonist (VKA). Double antiplatelet therapy (DAPT) was introduced in parallel to the transition from bail-out to elective coronary stenting. The fact that the observed stent thrombosis rate rapidly dropped to less than $5 \%$ was erroneously attributed to the DAPT and perhaps the simultaneously recommended high-pressure balloon stent implantation while it was basically the reflection of elective rather than bail-out stenting.

Subsequently, VKA was banned to make way for DAPT as the new overemphasised post-stent medical treatment standard. Uncritically, the problem of stent thrombosis, particularly during the first months, was accepted as a price to pay for less in-hospital lesion

\section{Figure 2}

Histological (courtesy Michael Joner, MD) and graphical depiction of clinically relevant stent features. The first generation drug-eluting stents, Cypher (sirolimus-eluting [S-ES]) and Taxus (paclitaxel-eluting [P-ES]), had an overly thin coating of the stent struts due to overdosing of the antiproliferative drug effecting an increased thrombosis potential due to late erosions or fissures of the thin coat. The Taxus stent in addition showed a nonhomogenous endothelial proliferation with some overproliferative areas causing restenosis (best depicted in the longitudinal section at the top). The current generation DES like Endeavor (zotarolimus-eluting [Z-ES]) and Xience (everolimus-eluting [E-ES]) engender a homogenous still thin but thick enough coat preventing both, restenosis and stent thrombosis. The bare metal stent (BMS) in comparison at the right has a homogenous but overly thick coat unlikely to erode or fissure and cause thrombosis but engendering some degree of restenosis.

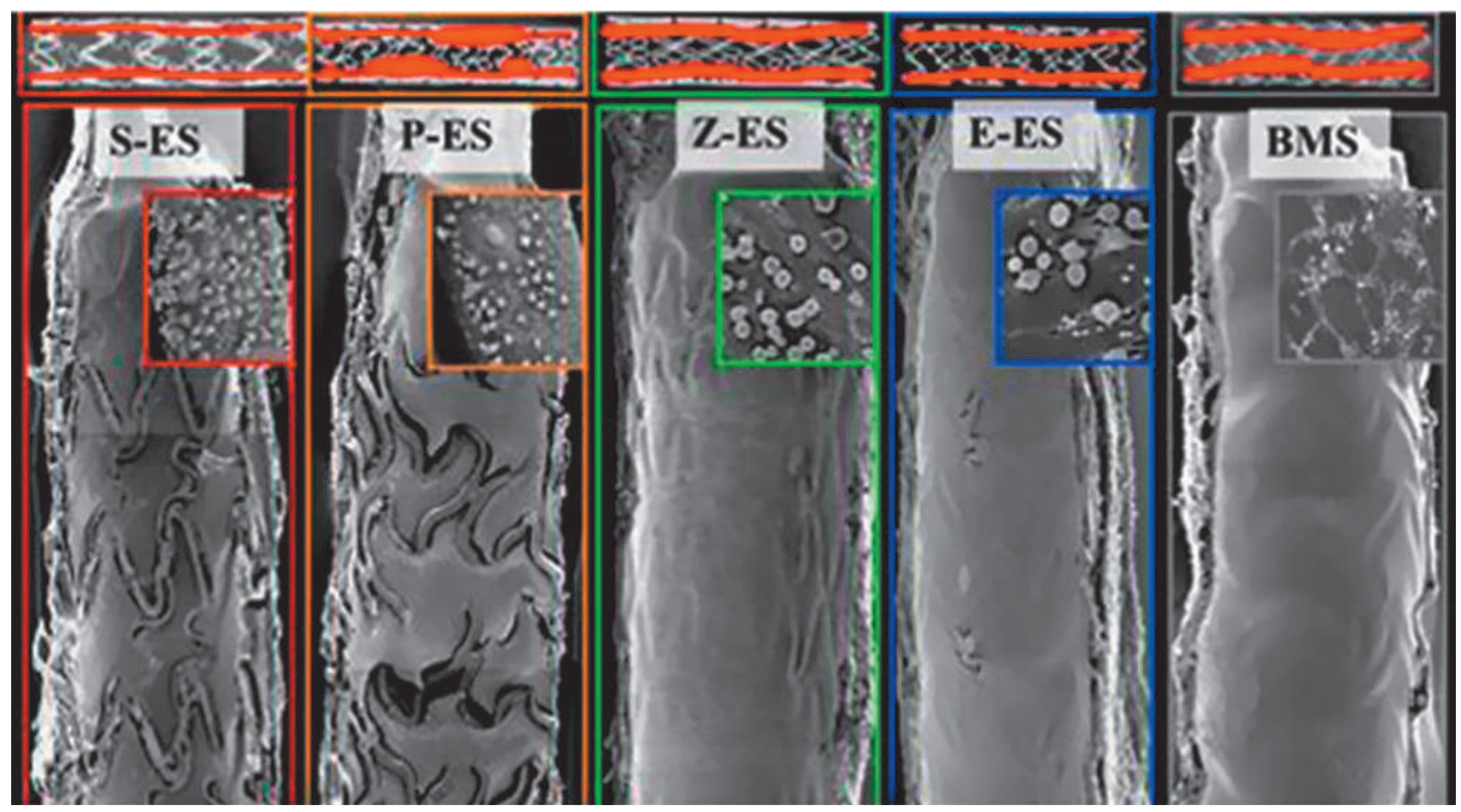



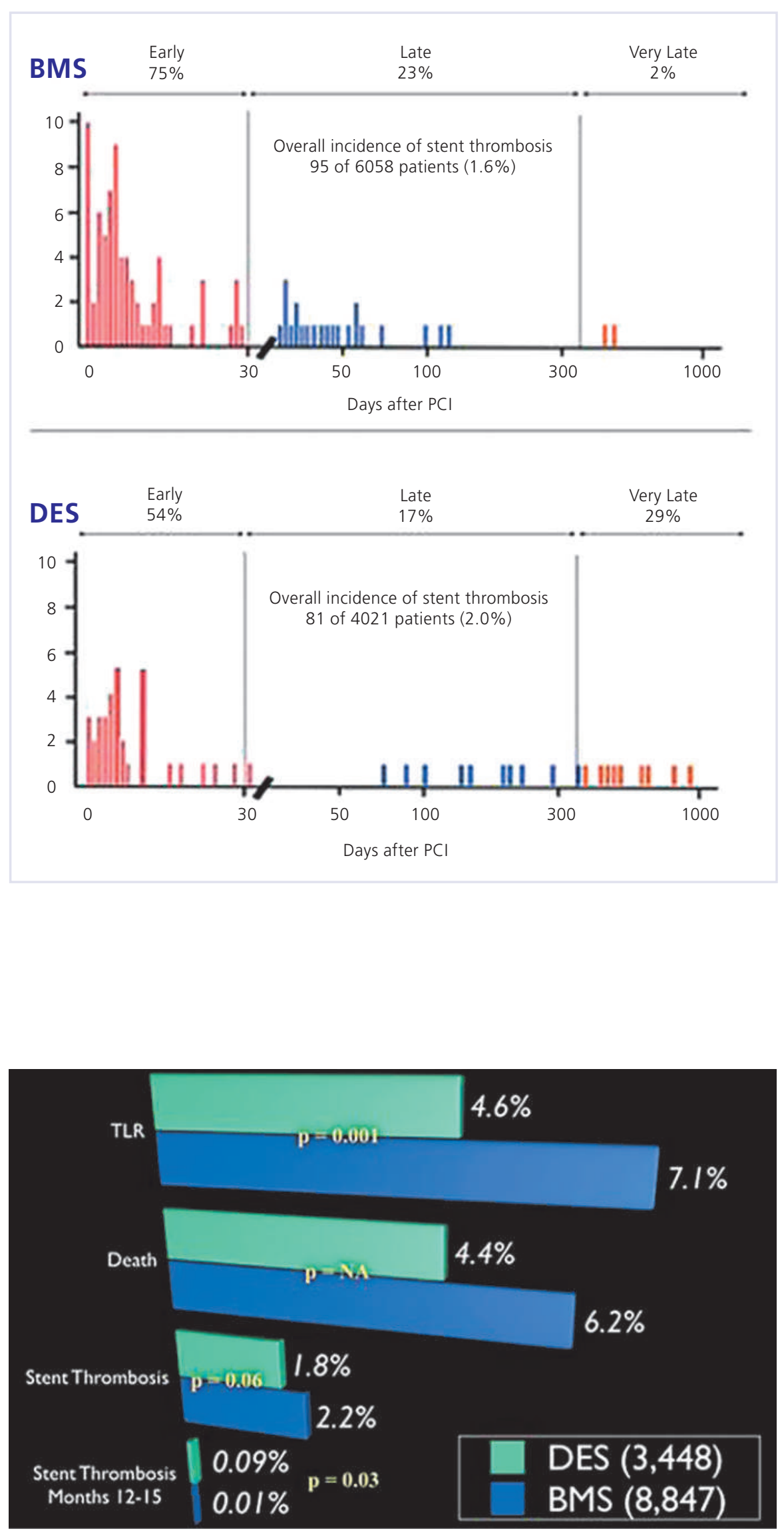

\section{Figure 3}

Stent thrombosis with bare metal stents (BMS) [14] and drug-eluting stents (DES) [15] during the first three years. While the overall incidence is comparable, there are clearly more late and very late stent thromboses with DES than with BMS which was recognised and repeatedly highlighted. Equally apparent but ignored was the fact that there were fewer early stent thromboses with DES.

\section{Figure 4}

Prognostic outcome of patients treated with drug-eluting stents (DES, number of patients in parentheses) or bare metal stents (BMS) in a nationwide Danish registry with a 15-month follow-up. The significantly increased risk of stent thrombosis with DES during months 12 to 15 was presented but not sufficiently declared as an isolated finding. As shown here in the overall context, it is of negligible importance and DES are superior on all other accounts. 
thrombosis and reduced restenosis, the two major banes of POBA that on the other hand knows no lesion thrombosis after hospital discharge. Stent thromboses after one year were rare because by then a thick neointimal coat usually covered the entire BMS (fig. 2).

When DES were announced for clinical use, we and others were warned to expect more late stent thromboses due to the thinner neointimal coverage of the stents, the targeted effect of the antiproliferative drug on DES [13]. This prophecy was fulfilled (fig. 3) [14, 15] and in 2006 the situation went out of control. Then the uncontested increased risk of stent thrombosis at around 1 year of follow-up was inappropriately highlighted in an isolated manner by several reports [16, 17]. They failed to point out clearly enough that they focused on the time around 1 year and they did not acknowledge the respective advantage in favour of DES accrued over the first year. Figure 4 exemplifies the distorted presentation of the real but rather petty DES thrombosis problem [16].

Unfortunately this capped the uprise of DES use worldwide, quite to detriment of patients. It also led to the false general opinion that patients at a particular risk of stent thrombosis early on, like those needing major surgery soon after stenting and patients unlikely to comply with DAPT, should get a BMS rather than a DES. While this was wrong already with first generation DES, it has become absurd with modern DES. For these, the lower early stent thrombosis risk compared to BMS is even more marked and there is no longer any catch-up in thrombosis after the first year. While BMS stent thrombosis rate at two years is $1.4 \%$, it was $1.3 \%$ for first generation DES and is $0.6 \%$ for contemporary DES [18]. In a long-term follow-up study, even the first-generation sirolimus-eluting Cypher stent maintained a lower stent thrombosis rate than BMS even at 7 years in over 10000 patients [19]. All this is independent of the presence or duration of DAPT. To the contrary, a study on the benefit of prolonged DAPT showed that DES are less benefiting from it than BMS [20]. Animal studies comparing the thrombosis rates of a large variety BMS and of DES proved a lower propensity for thrombosis of DES and underlined that this ran against common perception [21]. An explanation for reduced early stent thrombosis of DES may be the polymer, the drug container coating the metal. It may be anti-thrombogenic while the stent is not yet covered by endothelium. Figure 2 plausibly explains the disparate risks of stent designs to produce restenosis or stent thrombosis.

Several papers examined the incidence of myocardial infarction as a surrogate of stent thrombosis of BMS versus DES in patients undergoing surgery after stenting, which usually requires interruption of DAPT if not of all antiplatelet therapy. They again disproved the general opinion that BMS are safer and documented beyond reasonable doubt and once and for all that, indeed, DES are safer [22-25].

\section{Conclusion}

It is about time to acknowledge the abundant literature testifying to the fact that DES are superior to BMS on all accounts without any exception and to enjoy the superb results with their modern versions. Current DES feature unparalleled user-friendliness, need for re-intervention in the low single digits, and risk for stent thrombosis of about $1 \%$ in the first year and practically zero after that with little dependences on DAPT per se or on DAPT duration. This touches on perfection and the currently reprimandable attitude to stent every coronary lesion approached needs no longer be frowned upon. Hence, the saying that absorbable stents are the future of PCI and will always be is quite fitting as besting modern metal DES may likely prove impossible.

\section{References}

1 Roguin A. Stent: the man and world behind the coronary metal prosthesis. Circ Cardiovasc Interv. 2011;4:206-9.

2 Puel J, Joffre F, Rousseau H, Guermonprez B, Lancelin B, Valeix B, et al. Endo-prothèses coronariennes auto-expansives dans la prévention des resténoses après angioplastie transluminale. Arch Mal Coeur. 1987;8:1311-2.

3 Detre KM, Holmes DR, Jr., Holubkov R, Cowley MJ, Bourassa MG, Faxon DP, et al. Incidence and consequences of periprocedural occlusion. The 1985-1986 National Heart, Lung, and Blood Institute Percutaneous Transluminal Coronary Angioplasty Registry. Circulation. 1990;82:739-50.

4 Schömig A, Kastrati A, Mudra H, Blasini R, Schuhlen H, Klauss V, et al. Four-year experience with Palmaz-Schatz stenting in coronary angioplasty complicated by dissection with threatened or present vessel closure. Circulation. 1994;90:2716-24.

5 Brophy JM, Belisle P, Joseph L. Evidence for use of coronary stents. A hierarchical bayesian meta-analysis. Ann Intern Med. 2003;138:77786.

6 Kiemeneij F, Serruys PW, Macaya C, Rutsch W, Heyndrickx G, Albertsson $\mathrm{P}$, et al. Continued benefit of coronary stenting versus balloon angioplasty: five-year clinical follow-up of Benestent-I trial. J Am Coll Cardiol. 2001;37:1598-603.

7 Zidar JP, Fry E, Lambert C, Rubinstein R, Raizner AE, Fischell TA, et al. The VENUS trial: a multi-center registry of the Cordis Bx VELOCITY Stent. Am J Cardiol. 2000;86(8 Suppl 1):17i.

8 Serruys P, Ijsselmuiden S, Hout B, Vermeersch P, Bramucci E, Legrand $\mathrm{V}$, et al. Direct stenting with the Bx Velocity balloon-expandable stent mounted on the raptor rapid exchange delivery system versus predilatation in a European randomized trial (VELVET). Int J Cardiovasc Intervent. 2003;5:17-26.

9 Morice MC, Serruys PW, Sousa JE, Fajadet J, Ban Hayashi E, Perin M, et al. A randomized comparison of a sirolimus-eluting stent with a standard stent for coronary revascularization. N Engl J Med. 2002;346: 1773-80.

10 Moses JW, Leon MB, Popma JJ, Fitzgerald PJ, Holmes DR, O'Shaughnessy C, et al. Sirolimus-eluting stents versus standard stents in patients with stenosis in a native coronary artery. N Engl J Med. 2003;349:1315-23.

11 Schofer J, Schluter M, Gershlick AH, Wijns W, Garcia E, Schampaert E, et al. Sirolimus-eluting stents for treatment of patients with long atherosclerotic lesions in small coronary arteries: double-blind, randomised controlled trial (E-SIRIUS). Lancet. 2003;362:1093-9.

12 Meier B. New devices for coronary angioplasty: The Emperor's new clothes revisited. Am J Med. 1995;98:429-31.

13 Togni M, Windecker S, Meier B. Treatment of Restenosis. Curr Interv Cardiol Rep. 2001;3:306-10.

14 Wenaweser P, Rey C, Eberli FR, Togni M, Tuller D, Locher S, et al. Stent thrombosis following bare-metal stent implantation: success of emergency percutaneous coronary intervention and predictors of adverse outcome. Eur Heart J. 2005;26:1180-7. 
15 Wenaweser P, Daemen J, Zwahlen M, Van Domburg R, Jüni P, Vaina S, et al. Incidence and correlates of drug-eluting stent thrombosis in routine clinical practice: 4 -year results from a large 2 -institutional cohort study. JACC. 2008;52:1134-40.

16 Camenzind E. Treatment of in-stent restenosis - back to the future? N Engl J Med. 2006;16:2149-51.

17 Jensen LO, Maeng M, Kaltoft A, Thayssen P, Hansen HH, Bottcher, et al. Stent thrombosis, myocardial infarction, and death after drug-eluting and bare-metal stent coronary interventions. J Am Coll Cardiol. 2007;50:463-70.

18 Sarno G, Lagerqvist B, Fröbert O, Nilsson J, Olivecrona G, Omerovic E, et al. Lower risk of stent thrombosis and restenosis with unrestricted use of "new-generation" drug-eluting stents: a report from the nationwide Swedish Coronary Angiography Registry (SCAAR). Eur Heart J. 2012;33:606-13.

19 Natsuaki M, Morimoto T, Furukawa Y, Nakagawa Y, Kadota K, Yamaji $\mathrm{K}$, et al. Late adverse events after implantation of sirolimus-eluting stent and bare-metal stent: long-term ( $5-7$ years) follow-up of the coronary revascularization demonstrating outcome study-kyoto registry cohort-2. Circ Cardiovasc Interv. 2014;7:168-79.

20 Valgimigli M, Borghesi M, Tebaldi M, Vranckx P, Parrinello G, Ferrari R. Should duration of dual antiplatelet therapy depend on the type and/ or potency of implanted stent? A prespecified analysis from the PROlonging Dual antiplatelet treatment after Granding stent-induced Intimal hyperplasia studY (PRODIGY). Eur Heart J. 2013;34:909-19.
21 Kolandaivelu K, Swaminathan R, Gibson W, Kolachalama V, NguyenEhrenreich K, Giddings V, et al. Stent thrombogenicity early in highrisk interventional settings is driven by stent design and deployment and protected by polymer-drug coatings. Circulation. 2011;123:1400-9.

22 Van Kuijk J, Flu W, Schouten O, Hoeks S, Schenkeveld L, de Jaegere P, et al. Timing of noncardiac surgery after coronary artery stenting with bare metal or drug-eluting stents. Am J Cardiol. 2009;104:1229-34.

23 Tokushige A, Shimoni H, Morimoto T, Furukawa Y, Nakagawa Y, Kadota $\mathrm{K}$, et al. Incidence and outcome of surgical procedures after coronary bare-metal and drug-eluting stent implantation: a report from the CREDO-Kyoto PCI/CABG registry cohort-2. Circ Cardiovasc Interv. 2012;5:237-46.

24 Cruden N, Harding S, Flapan A, Graham C, Wild S, Slack R, et al. Previous coronary stent implantation and cardiac events in patients undergoing noncardiac surgery. Circ Cardiovasc Interv. 2010;3:236-42.

25 Hawn M, Graham L, Richman J, Itani K, Henderson W, Maddox T. Risk of major adverse cardiac events following noncardiac surgery in patients with coronary stents. JAMA. 2013;310:1462-72. 